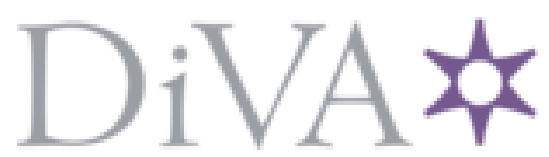

http://www.diva-portal.org

This is the published version of a chapter published in From CSCW to Web 2.0: European Developments in Collaborative Design.

Citation for the original published chapter:

Larsson, A., Ericson, Å., Larsson, T., Isaksson, O., Bertoni, M. (2010)

Engineering 2.0 - Exploring lightweight technologies for the virtual enterprise.

In: From CSCW to Web 2.0: European Developments in Collaborative Design (pp. 173-191).

Springer

http://dx.doi.org/10.1007/978-1-84882-965-7_9

N.B. When citing this work, cite the original published chapter.

Permanent link to this version:

http://urn.kb.se/resolve?urn=urn:nbn:se:bth-11253 


\title{
Chapter 9 \\ Engineering 2.0: Exploring Lightweight Technologies for the Virtual Enterprise
}

\author{
Andreas Larsson, Åsa Ericson, Tobias Larsson, Ola Isaksson, \\ and Marco Bertoni
}

\subsection{Introduction}

In a traditional business partnership, the partner companies are under contractual obligation to share data, information, and knowledge through one or several information systems that the leading firm decides. In such a case, the issue of sharing "whatever needs to be shared" is settled in contracts before any action is taken, however, also giving the implications that sharing expertise becomes a heavy and time-consuming activity. In turn, it can be argued that the heavy administration affects the lead time of product development negatively since the necessary input flows are delayed. In addition, the adaptation to certain predefined collaborative information systems is both expensive and resource-consuming (e.g., educating staff to use them). Also, the system might not be adaptable to the existing internal technology structure, causing a "translation" procedure, again taking up resources. Another structure for collaboration is a network or alliance of independent partner companies. One motivation for a network structure is that the partners can join or leave it more easily. A reason for joining and staying is an implicit sense of knowledge sharing (Tomkins 2001) and access to a "winwin" environment. Furthermore, the partners can be linked by information technology, i.e., forming a virtual structure rather than a physical one. The technologies provide the channels with additional knowledge. In a best-case scenario, a company would get access to a wide range of useful competences, and in a worst-case scenario the company would be drained of its core competences. Accordingly, at least two considerations for joining a partner network can be considered. First, the resources needed to couple the technologies have to be reasonable, due to the underpinning logic of going in and out of more than one network. Second, the company has to identify its knowledge base and evaluate the prospective gains and losses of sharing its expertise.

Engineering work tasks are currently well supported by computer applications, e.g., CAD (Computer Aided Design), CAE (Computer Aided Engineering), PDM

\footnotetext{
A. Larsson $(\varangle)$, A. Ericson, T. Larsson, O. Isaksson, and M. Bertoni

Lulea Technical University, Sweden

e-mail: Andreas.c.Larsson@1tu.se
} 
(Product Data Management), and PLM (Product Lifecycle Management). CAD supports a visualization of the product, e.g., a 3D technical drawing and enables the engineers to validate the design and all changes against certain technical rules. CAE also offers a visualization of the product and focuses more clearly on simulation and optimization techniques to elaborate on, for instance, the distribution of stresses and displacements on a component in a welding process. PDM/PLM systems support the management of the entire life cycle of a product. A product life cycle is, commonly, described as going from an idea, via design, manufacture, distribution, and use to recycling; thus PDM/PLM systems manage not only product information but also customer and business information. These applications or their descriptions are not intended to be exhaustive, but rather to provide a sense of the nature of the information technology that is used in modern product-development companies.

It can be argued that one misconception of engineering work is that the very embodiment of product properties into 3D models and data structures of the above kind implies that all the relevant data, information, and knowledge have been captured and can serve as a base for decisions. Engineering work, which can be viewed as knowledge work, relies on expertise and competences that relate to the product that is being developed, i.e., the physical thing. However, knowledge work also has a social dimension, e.g., learning and experiencing. The assessment of the result from a number of distinct computer analyses, i.e., "putting two and two together," and what engineers know by experience influence many decisions in product development, but this kind of design reasoning is usually not made visible in the same way as technical product information. Of course, one constraint is that such knowledge is hard to express and consequently problematic to capture and formalize into information systems. Further, if captured and formalized into a knowledge base or expert system, the contents become "lagged" or "old" over time. The maintenance of the contents is commonly a huge effort where a number of engineers are struggling to keep it up-to-date. Traditional kinds of systems insist on a similar approach, and a drawback is that the practice contributes to a situation where the content of the systems and the enhancement of it are separated from those who deal with the knowledge generation processes in their daily, regular work activities. In general, this describes a knowledge management perspective, where the focus is on reuse of knowledge, and the information system is used to monitor and control the process.

Another view is a knowledge sharing view, where the focus is to spur and nurture knowledge creation (Ackerman et al. 2003) and, accordingly, the supporting technologies should also enable experiences, design reasoning, and lessons learnt to be shared. In engineering collaboration, such support seems to be lacking in the commonly used information systems. However, lightweight technologies are used by people interacting, generating, and sharing knowledge over the Internet. In this chapter, we will make the assertion that lightweight technologies can have a serious potential when it comes to effectively sharing knowledge between actors partaking in product development in a virtual context. Thus, the purpose of this chapter is to highlight opportunities, describe the possibilities, and discuss the ways in which lightweight technology can be adapted to be supportive in a business-to-business network. 
Proposing lightweight technologies, e.g., wikis, tag clouds, and mashups, in an industrial context is sometimes controversial; we would like to clarify our intentions in this chapter. First, note the word "adapted" in the purpose above. This means that we will explore what can be learnt from lightweight technologies, discuss the potential for an industrial application, and suggest modifications that need to be done. Second, we make a distinction to the commonly used technologies, e.g., $\mathrm{CAD} / \mathrm{CAE} / \mathrm{PDM} / \mathrm{PLM}$, by calling them "heavyweight"; this is not done to favor one over the other. We like to distinguish the efforts in applying and using them. Also, we do not intend to argue for a replacement of "heavyweight" technologies; rather, we argue that both are needed and complement each other. A main point in such a discussion is that lightweight technologies are rarely considered as useful in an industrial context.

A delimitation of the scope in this chapter is that we focus on understanding the kinds of problems that occur and can occur when the intention is to share knowledge. We do not attempt to produce technical requirements for the design of a solution, nor do we evaluate the technologies. Another delimitation of this chapter is its focus on "engineers"; however, "what engineers do" is framed by a changed view on the product they are going to develop. We will present the idea of life-cycle commitments, which are one trigger for change in the traditional work of engineers. A life-cycle commitment is based on a product-development process that has the outcome of added value for customers. Accordingly, engineers take on a larger part of the intangible value creation activities when designing the physical thing. Also, the typical engineering work increases in scope and is challenged by relational complexity when collaborating in partner networks, or, as outlined in this paper, a virtual enterprise. These parts motivate the discussion on lightweight technologies, which compose the main part of the chapter. The discussion is delimited to focus on opportunities and possibilities; so while we understand the problems with intellectual property rights, the importance to clarify who owns what knowledge assets and how to both protect and share knowledge, we do not include this in our discussion.

The discussion in this paper has evolved in our research context, which includes close collaboration with industrial companies, hence also providing access to empirical cases. The aspects of knowledge - management and sharing - have provided an overarching theme for our research interest during the last 10 years. In recent time, our participation in two large research projects, have provided access to a total of nine international companies, and numerous people from these companies. For example, we have conducted a number of multiday workshops, participated in virtual meetings, made company visits to perform interviews on both a formal and an informal basis. The paper draws on data from a number of industrial development projects related to several different products in various industry segments - ranging from the development of manufacturing tools and industrial drive systems, to aircraft engines and armored terrain vehicles. So, the identification of the problematic situations has been noticed in the larger empirical context. The excerpts that are presented in this paper are transcribed from taped interviews performed at various companies. The excerpts are chosen based on their potential 
to represent the kinds of problems that typically are experienced when sharing knowledge and extend the offerings toward life-cycle commitments.

\subsection{Life-Cycle Commitments}

Framed by a Product-Service Systems paradigm (Bains et al. 2007) a movement toward extended business models is taking place in industry. Here, the term "lifecycle commitments" is used to cover the various concepts used in industrial companies. The name differs, but there are common features, e.g., an increased interest in providing "functions" rather than selling "hardware," and a general focus on providing added value to customers. A life-cycle commitment which is provided by the aircraft engine manufacturer Rolls-Royce is called "Total Care" and aims to deliver "power by the hour" in order to "improve product availability and reduce the cost of ownership by tying a supplier's compensation to the output value of the product generated by the customer (buyer)" (Kim et al. 2007).

One consequence of such life-cycle commitments is that customers and providers are taking a step closer to each other in the value chain, hence also creating long-term business relationships. This is a challenge, insofar as many consumer-product companies can reverse-engineer competitors' products in a matter of days. Another consequence of this performance-based business model means that customers pay for the result of the product use, i.e., what ultimately adds value. Further, time and material associated with repairs and overhauls are incorporated into a life-cycle commitment.

From the provider's perspective this means that maintenance becomes a cost instead of a profit. Considering that airline companies spend on average US\$ 870 per flight hour in direct maintenance costs, with engines representing over $40 \%$ of that cost, it is safe to assume that the companies need to provide attractive offers that are profitable for all partners. A jet engine could be kept in service for as much as 30-40 years, and providing a function means that the functional product provider cannot longer, in the traditional sense, earn money on the once lucrative aftermarket. Also, the aftermarket is incredibly competitive even in the current situation. Essentially, to create a win-win situation for providers and customers, a life-cycle commitment has to be considered from a product-development perspective. Although many products in today's marketplace might be sold as functions, they are rarely developed with a function view, i.e., focusing on use of performance to provide perceived value.

Life-cycle commitments do, on one side, mean that the business is based on a long-term relationship. On the other side, it indicates an increased interest and incentive to collect and use information from the entire life-cycle and, in particular, make use of downstream information early on (Boart 2005). That is, information about how customers are using the physical product becomes vital, and the long-term horizon adds an interest to gain insights into the basic reasoning that makes the customer link the use of performance to perceived added value. 
The view of a product is, from a customer perspective, holistic and encompassing (Mello 2002), while from a traditional development perspective it is broken down into a view of a service or a physical thing.

In addition to the business development processes, such a perspective makes two separate development processes discernible. A product development process for life-cycle commitments has to consider these processes in an integrative way in early development. In a broad sense, decisions concerning whether or not to provide life-cycle commitments have to be made, as well as decisions for how to technically solve the long-term provision of functions. To what extent should services be "designed-in" or "added on," and what competences and knowledge are needed for the development and the provision of use of performance. So, the scope of early product development activities rapidly changes to encompass a wider range of data, information, and knowledge that is not readily available in a traditional product-development process.

To provide an "ideal" life-cycle commitment that is capable of delivering use of performance during 30-40 years, as in the case with a jet engine, a risk- and revenue-sharing environment together with business partners is a key. In general, the formation of a joint venture can be a solution, where a structure of a network of partners supported by technologies is a specific way. Within the frame for the discussion in this paper, two main challenges need to be addressed to achieve successful collaboration, namely (1) how to effectively share relevant and valid knowledge in time and (2) how to capture and make use of it. Hence, companies need to rethink how knowledge is created and shared across the many boundaries of the global value chain.

\subsection{Knowledge Sharing in the Virtual Enterprise}

In the case of a joint venture, here a Virtual Enterprise (VE), the issue of what knowledge to share and how to share it needs to be resolved. A VE is essentially a network of independent companies, including suppliers, customers, and even competitors, that are "linked by information technology to share skills, costs, and access to one another's markets. It will have neither central office nor organization chart. It will have no hierarchy, no vertical integration" (Byrne 1993). Thus, a basic idea is that no single company in the partnership can impose their preferred way to collaborate. The idea of a network structure highlights a swift and easy way to get linked to different business partners. Basically, to impose a preferred technological way to get access spoils the idea of easily getting in our out of the network.

Defined in logical terms, not physical, the VE is based on the idea of organizations gaining access to more resources than they currently have available, without having to expand. Further, a VE is extended to encompass a network of partners and suppliers that work together to reach common goals. In this environment there is unlikely to be any single partner that can decide the infrastructure, tool set, or processes to be used. 
Ray Noorda, founder of Novell, noted that companies need to simultaneously compete and cooperate, thus coining the term coopetition (Brandenburger and Nalebuff 1997) which essentially deals with the interplay between competition and cooperation. Partners in a VE may choose to work together with the aim to collectively enhance their performance by sharing resources, risks, and rewards - and they may, at the same time, work independently to improve their own performance and market attractiveness. For instance, two independent airline carriers, such as Singapore Airlines and Qantas Airlines, can compete against each other for landing slots, gates, freight contracts, and passengers, while cooperating to share the development cost of the Airbus A380 aircraft that are part of their current fleet expansion. On a larger scale, these companies are also part of separate airline alliances, the Star Alliance and the oneworld Alliance, which further blurs the lines between who is a customer and who is a supplier. Note that a jet engine manufacturer, such as Rolls-Royce, might develop engines to be used on both Airbus and Boeing aircraft, which are ordered by different airliners, which are partners in different airline alliances, etc. For example, the V2500 aero engine family is provided by International Aero Engines (IAE), a joint venture including Pratt \& Whitney, Rolls-Royce, MTU Aero Engines, and the Japanese Aero Engines Corporation (www.v2500.com). The CFM56 aero engine product line is developed by CFM International, a joint venture between GE and Snecma (www.cfm56.com), and the GP7200 engines powering the Airbus A380 are a result of the Engine Alliance (www.enginealliance.com), a joint venture between GE and Pratt \& Whitney.

Since coopetition, i.e., "collaborating with the enemy," is becoming increasingly common in the domain of global product development, being able to handle the rapid transformations in and out of a VE is critical. Each partner company in the network needs to know, in terms of knowledge sharing, what they can bring into the partnership and what they can take from it. Accordingly, a cohesive and intentional life-cycle perspective also on knowledge is needed.

\subsection{The Need to Raise the Knowledge Baseline}

The starting position for a heterogeneous development team consisting of people from different departments, different companies, etc., means that the team, as a whole, usually does not have a previous history of working together - there are fundamentally no "shared assumptions" of how to collaborate within the team or, in the case of new products included in a life-cycle commitment, no "shared vision" for what to develop. Rather, there are as many assumptions and visions as there are people involved. One of the success factors in this kind of collaboration is the ability to effectively and seamlessly assemble and utilize, drawing from the different perspectives of the VE partners, their pool of resources, the various combinations of specific capabilities to be applied in the project at hand. Furthermore, there is an inevitable flux of team members over time in product development projects, so knowledge not only needs to be utilized, but also made available into a larger context than within the team. 
This points out the issues of how to make structural knowledge capital out of the human knowledge capital and make it available internally and externally to make sure that knowledge assets can be effectively shared across organizational and departmental boundaries. These challenges are part of the activities to raise the knowledge baseline in joint development projects. Effective knowledge sharing is challenged by more distances than the geographical, and differences include language, culture (both "corporate" and "local"), educational background, government regulations, and time zones. There are several aspects that can impose negative influence on the performance of cross-boundary collaboration in development teams. Issues of how to build trust, rapport, and respect to bridge these differences is identified as crucial (Larsson 2005). Another crucial point when the product has a long life-cycle, as in the aerospace industry, is that knowledge assets need to be maintained for a period of time that could extend several years after the development project has been concluded. Take Pratt \& Whitney's JT8D engine, for example, which has been in use since the early 1960s in different variants.

Also, the movement of data, information, and knowledge is vital for a competitive total life-cycle commitment. Knowledge from the "later" phases of the product life-cycle (i.e., production, distribution, use, maintenance, recycling, etc.) now needs to be used as a knowledge foundation in the earlier phases of the product development process. It is most advantageous to make changes at the preliminary design phase, since it will become more expensive, more difficult, or even impossible to compensate or correct the shortcomings of a poor design concept in the later life-cycle phases. So, in order to provide products that, in life-cycle commitments, truly meet the full range of the actors' demands and needs, it is highly important to investigate how downstream knowledge could be made available to all actors, to improve early-stage decision making in cross-disciplinary product-development teams. For example, the deployment of Knowledge Based Engineering applications (Boart 2005: 36) enables companies to move downstream information upstream, essentially making information of the result of later activities available at an earlier stage of development. Several iterations of "what if" studies can be conducted already in the conceptual phase, which will form a useful knowledge base from which to more accurately predict life-cycle costs, etc.

\subsection{Engineering 2.0: Lightweight Technologies in Engineering}

As stated in the introduction to this chapter, we make the assertion that lightweight technologies show serious potential when it comes to effectively sharing knowledge between actors partaking in product development in a VE. Here, the term "lightweight" principally means that the technologies: (1) require little time and effort to set up, use, and maintain (i.e., lowering the threshold for adopting the technologies); (2) do not impose a predefined structure (i.e., letting structures evolve over time as an almost organic response to the activities, practices, and interests of the knowledge workers that use these technologies as part of their everyday work; and (3) support informal communication also in absence of physical 
proximity (i.e., by capturing also the subtle, spontaneous, and multidimensional messages that characterize personal interaction).

Since this work draws its context from the fields of engineering and product development in primarily business-to-business situations, we have chosen to summarize these lightweight technologies in the term "Engineering 2.0" - borrowing from the concepts of "Web 2.0" (O'Reilly 2005) and "Enterprise 2.0" (McAfee 2006).

One of the key lessons of the Web 2.0 era is this: Users add value. But only a small percentage of users will go to the trouble of adding value to your application via explicit means. Therefore, Web 2.0 companies set inclusive defaults for aggregating user data and building value as a side-effect of ordinary use of the application. As noted above, they build systems that get better the more people use them. (O’Reilly 2005)

The simplicity of Web 2.0 technologies offers a few key characteristics that have particular relevance for the highly distributed, highly cross-functional Virtual Enterprise. To reap the benefits of Web 2.0, companies need to (1) support lighweight programming models that allow for loosely coupled systems (i.e., in line with the loosely coupled VE network); (2) support syndication rather than coordination of data (i.e., content will flow from the bottom-up rather than from the topdown); and (3) support reuse and remixability in an open-source model (i.e., content can be used for other purposes than for which it was originally intended).

Similarly, McAfee's concept of 'Enterprise 2.0' includes “new digital platforms for generating, sharing and refinding information that are focusing not on capturing knowledge itself, but rather on the practices and output of knowledge workers" (McAfee 2006). Engineering 2.0 is specifically targeting how these lightweight technologies and approaches could benefit globally dispersed engineering teams, working in business-to-business contexts of the VE kind, where the available technology support for knowledge sharing still mainly centers around CAD/CAE/PDM/ PLM systems, complemented with online collaborative workspaces and web conferencing systems to support both asynchronous and synchronous collaboration.

As noted earlier, there are a number of unique features of this emerging industry context that highlight the need for complementary knowledge sharing technologies:

1. Virtual Enterprises are "loosely" coupled networks of independent partners, established on a project-by-project basis.

2. Knowledge workers in enterprise-wide teams do not normally have a shared history of working together.

3. Knowledge workers in enterprise-wide teams do not normally have a shared knowledge base with lessons learned, best-practices, etc.

4. Knowledge workers move in and out of enterprise-wide teams as different competencies and capabilities are needed.

5. Knowledge workers in enterprise-wide teams do not normally have a shared set of technological systems to create, store, and share knowledge.

6. Development of "functions," rather than "hardware," as part of total life-cycle commitments radically changes the scope and objectives of engineering activities. 
7. Knowledge workers will need to increasingly work in highly cross-functional, cross-disciplinary, enterprise-wide teams.

8. Knowledge workers will need to develop closer relationships with customers and suppliers, to better understand the desired "function" to be developed.

9. Knowledge workers will need to improve their understanding of their contribution to the overall development and product life cycles.

10. Knowledge workers will need to make their knowledge available to a much larger audience than before, and will also need to use knowledge from many more sources than before.

Due to these characteristics, our research focuses particularly on knowledge that currently resides outside of the traditional scope of product development teams. We have chosen to refer to such knowledge as "downstream knowledge," since we are mainly interested in identifying and utilizing knowledge assets that normally would not enter the scene until after a design concept has already been selected. For example, the same fundamental knowledge assets might be used for the purposes of both product development and opportunity management, but since there are different competencies involved with different goals and motivations, it is crucial to be able to share this structuralized knowledge on an adequate level of detail or abstraction depending on each particular setting.

An important aspect of these knowledge assets is that they can be found in a wide range of professional domains - both within the own company, and at customers and partners. Thus, the overall research agenda seeks to address how boundary-crossing teams across the VE can decrease the start-up time for new product-development projects by rapidly identifying and effectively utilizing a shared knowledge base from day 1 (i.e., rather than starting from "scratch"). Also, it addresses how these various teams can successfully create, share, and utilize "generic" knowledge, i.e., making sure that the knowledge assets they create are easily available to other teams in the VE, regardless of what domain of expertise they are working in.

\subsubsection{From Weak to Potential Ties}

It has been observed that engineers and scientists very often turn to a person for information rather than to a database or a file cabinet, and people seem to rely heavily on colleagues that they know and trust. Our research indicates that "knowing who knows" (Larsson 2005) is crucial in global engineering design teams and while that seems to be a commonly accepted feature of collaborative work, it also poses a severe threat to VEs, where this kind of "engineering know-who" (Larsson 2005) is not as easily developed as in more traditional enterprise settings. The increasing globalization and the influx of VE thinking means that engineers are working together with more people than ever before, but often with very limited knowledge of who they are actually working with, what their collaborators know, and to what extent they can be trusted. To achieve effective global design teams, it is crucial to address and deal with such issues of "social disconnectedness." 
In the context of manufacturing tool development, one of our informants noted that your ability to access and try to better understand customer needs fundamentally depends on whom you talk to in the customer organization. "The customer" is more than one person, and the answers vary from person to person, and are also dependent on the bias of the person who is asking the questions. A similar problem as highlighted by an informant at the industrial drive systems company:

Different functions meet the customer at different occasions. It is not easy to merge. Who has the complete picture? Customer value is dispersed across many different persons who have different information about the customer need. We have different persons at the customer site as well: technicians, purchasers, service-personnel, etc.

The concept of "weak ties" (Granovetter 1973) points to the value of establishing personal relationships that transcend local relationship boundaries both socially and geographically. For example, Granovetter's has indicated that a person looking for a job is, for certain professions, more likely to find a new job through an acquaintance rather than through a close friend, much because the acquaintance is more likely to move in other social circles, and is also more likely to possess other information than what you already have. So, this is particularly interesting when it comes to product-development activities, since that is a field where knowledge workers are explicitly interested in avoiding redundancy, and instead seek novelty and innovation. However, what would be the output if VEs could also better harness the power of "potential ties"? This notion includes:

a still-larger set of fellow employees who could be valuable to our prototypical knowledge
worker if only she knew about them. These are people who could keep her from re-inventing
the wheel, answer one of her pressing questions, point her to exactly the right resource, tell
her about a really good vendor, consultant, or other external partner, let her know that
they were working on a similar problem and had made some encouraging progress,
or do any of the other scores of good things that come from a well-functioning tie.
(McAfee 2007)

To really harness the knowledge that is dispersed across the VE, we need to recognize that the foremost experts on your products might not be on your payroll, and that there might be "hidden experts" around the enterprise, who are willing to volunteer outside of their official job description (Mayfield 2007). Also, of course, these potential ties could be "lead-users" (von Hippel 1986), in any part of the customer network, offering their advice and experience, whether you asked for it or not. Social networking software, such as LinkedIn or Facebook, and blogs and wikis are some of the ways in which engineers can both increase the density of their weak ties, and get connected to people with knowledge and experience that is new and possibly complementary rather than well-known and possibly redundant.

\subsubsection{From Personal to Public Benefit}

This chapter discusses lightweight technologies for knowledge sharing, and if a technology is perceived as "lightweight" or not naturally depends on the benefits 
derived from using such technologies. If the personal benefits are large, i.e., if the return on investment is high enough, users might even tolerate a slow and tedious system because the results are considered worth the extra effort. Similarly, even the lowest threshold could be considered too large if the results are not benefiting the user. One could argue that one of the reasons why many projects are poorly documented is that project participants have difficulties seeing the benefits of making this extra effort to capture rationale, experiences, lessons learned, etc. The people who have to do the extra work are normally not the people who will reap the benefits.

Tang et al. (2007) performed a study on how knowledge workers in a workplace environment store and manage files on their workplace computers, to see if any social patterns could be identified for the benefit of the company. The interesting thing here, from an Engineering 2.0 perspective, is that identifying these collaboration patterns did not require any additional work by the user. These patterns fell out of the work users are already doing in managing and storing files concerning information that they care about.

When attempting to lower the threshold for knowledge sharing, this is a highly appealing concept. If what people are doing as part of their everyday work produces traces and patterns of how they create, use, and share knowledge, why not use these traces and patterns to achieve public benefits across the VE? The social effects of using social software are sometimes unintended - which is something of a paradox. Knowledge workers do not have to put extra effort into sharing knowledge across social networks, but other people in the enterprise can still make sense and use of the traces they produce. In a VE context, where the social ties between knowledge workers are relatively few and weak, or even nonexistent, to start with, the ability to derive public benefits from personal actions is very interesting. Here, the concept of a "folksonomy" (Vander Wal 2007) makes sense, much because, as opposed to a taxonomy, people "are not so much categorizing, as providing a means to connect items (placing hooks) to provide their meaning in their own understanding", (Vander Wal 2007).

This provides opportunities to find emergent vocabularies and trends, and since information tagged for personal use can benefit other users (Golder and Huberman 2005) across the enterprise, this could allow knowledge workers to find people across the disciplinary, departmental, and organizational boundaries of the VE. Rather than relying entirely on up-front decisions about where in the enterprise to look for relevant knowledge and persons, finding people who tag items the same way they do, will allow knowledge workers to find social groups based on similar interests and ways of speaking and acting, rather than based on where they are placed in the organizational chart.

Paying attention to customers' everyday internal discussions about how they use, or even modify, a product could sometimes be more useful than first-hand accounts of what the customer need is perceived to be. On this point, one of our informants working in the manufacturing tool business commented that a source of innovation could be to look at situations when their customers actually use their products in unanticipated ways: 
[W] hen you look at the customers, they use certain hardware. There are situations where the customer has created the innovation by using the hardware in a certain way. Customers use the product differently than we had thought during development, and this can be an opportunity for innovation if we get to know this.

Apart from the benefits related to uncovering knowledge that you could not normally access through conventional interviews or observations, McAfee (2007) points to some interesting networking effects. As more people author, link, search, and tag information, the emergent structure becomes increasingly fine-grained: "They can make large organizations in some ways more searchable, analyzable and navigable than smaller ones, and make it easier for people to find precisely what they're looking for" (McAfee 2008). Here, concepts like tag clouds and social bookmarking could provide some of the lightweight capabilities to create public benefits from personal actions.

Lightweight technologies can also provide public benefits by increasing the common understanding of data and information stored inside and outside the organization. For instance, a document repository that contains most or all of the structured content produced by project members is typically undecipherable to people outside the project, to people who join the project after it is underway, and even to the original project members after time has passed (Grudin 2006). Since knowledge assets need to be maintained over time, it becomes increasingly important to record the contextual dimensions related to such content, since people may leave the organization, new partners may join the project, or new needs and requirements may emerge along the way. Lightweight technologies for knowledge sharing can support engineers in providing a context to the documentation stored in company databases. Blogs, for example, may be used to provide easily skimmed chronologically ordered records of the important events of a project (i.e., status changes, etc.) which may give knowledge users deeper understanding of how the work is being performed in the project and why it is being done in a certain way.

\subsubsection{From Predefined to Emergent Structures}

One of the defining features of lightweight technologies is that they do not impose a predefined structure to how these systems "should" be used. The intelligence of such systems is, instead, provided by users in low-threshold ways, where control is shared with users to create value. These technologies "are trying not to impose preconceived notions about how work should be categorized or structured. Instead, they're building tools that let these aspects emerge" (McAfee 2007). This means that there are no predefined roles, identities, or privileges; there are no workflow or process steps to follow; there are no specific data formats to adhere to, and there are no "required" fields to fill out. In the case of social bookmarking, people selfdefine their tags using words that mean something to them at the time, rather than categorizing their bookmarks according to a predefined taxonomy. For example, a customer statement that is captured in the context of a request for a maintenance engineer might be very interesting for an engineer working with concept development in the early phases of product development. 
However, if categorized only according to the corporate taxonomy, that piece of knowledge is likely to stay hidden in the "aftermarket" document archives. In our work in the aerospace domain, we have discussed that the "context" of a specific engineering activity is constantly emerging. If we, for example, take six relevant context dimensions (product, activity, project, gate, role, and discipline) into consideration, we can easily assume that engineers switch roles and projects as time goes by, and that different knowledge is needed at different gates and in different projects, etc. A challenge here is to make sure that just because the context dimensions might have been defined at one point in time, the knowledge attached to a certain context might be highly relevant in other contexts. If we can assist knowledge workers in contributing to a continuously emerging "folksonomy," rather than merely adhering to a predefined taxonomy, we should be able to better support the serendipitous discovery of information or knowledge that we would not have discovered by traditional searches in the enterprise knowledge base.

The absence of a predefined structure may also help in mitigating barriers to interoperability (Chen and Doumeingts 2004), which characterizes networked organizations. Traditional heavyweight systems are typically not designed for crosscompany collaboration and are difficult to integrate from a technological perspective, especially in a Virtual Enterprise situation. Moreover, such systems are typically characterized by a rigid taxonomy, which raises further barriers to interoperability from a conceptual point of view. Other barriers relate to human factors and behaviors incompatible with interoperability (Chen and Daclin 2006). The lack of an explicit definition of responsibilities and authorities in accessing, using, and maintaining these systems may constitute a strong barrier to cross-enterprise collaboration.

Lightweight technologies offer promising solution alternatives to increase the capability of networked organizations to effectively manage their knowledge assets in light of an increased interoperation. On one hand, they require little time and effort to be set up, used, and maintained and may be effortlessly aligned with related systems inside and outside of the organization. Moreover, since they do not impose a predefined syntax or semantics, they may contribute in lowering the conceptual barrier to interoperability. Problems such as polysemy, homonymy, and synonymy may find a solution over time, since the language (e.g., the folksonomy) evolves and people tend to adapt their jargon to the ones generated by others. Moreover, since lightweight technologies do not foresee predefined roles, identities, and privileges (i.e., wikis are open to authorship to all the team members) they may encourage the knowledge-sharing process in the earlier project steps, when roles and responsibilities are not yet clearly defined.

\subsubsection{From Lookup to Exploration}

While it is always beneficial for knowledge workers to know where to get their facts checked and their questions answered, it is not merely the Wikipedia effect we are striving for when discussing the potential benefits of an Engineering 2.0 approach. We believe that one of the most promising aspects of such technologies 
is that they can help knowledge workers move beyond known-item searches, fact retrieval, and question answering (Winograd 2008). In the context of product development activities of the kind described earlier, it is highly interesting to assist knowledge workers in more exploratory and investigative activities, which are "more concerned with recall (maximizing the number of possibly relevant objects that are retrieved) than precision (minimizing the number of possibly irrelevant objects that are retrieved)" (Marchionini 2006: 43).

One of our informants working with manufacturing tool development noted how the domains of product development and opportunity management were starting to become increasingly intertwined with the move toward developing "functions":

Earlier, we talked about product properties. Now it is about demands on the result of the product in use. This is needed to sell service-intensive products. We want to acquire the needs, and then be able to translate these into the products and services that need to be created.

Moving away from the hardware-centric view of product development means that we must give engineers (and other actors throughout the value chain) opportunities for serendipitous knowledge discovery, where they can "stumble upon" relevant knowledge, where they can browse a wide variety of topics that makes sense to others, and where they can gain a deeper understanding of what knowledge other people find useful and how they choose to deploy that knowledge. When we cannot easily find a match between a well-defined "need" and a welldefined "product property," lightweight technologies could help in exploring a wide range of opportunities, from a wide range of perspectives, with very little effort.

\subsubsection{From Directional to Intersectional}

Sir John Rose, chief executive of Rolls-Royce PLC, talks about how Rolls-Royce outsources and offshores about $75 \%$ to its global supply chain, keeping the $25 \%$ which are the "differentiating elements ... the hot end of the engine, the turbines, the compressors and fans and the alloys, and the aerodynamics of how they are made" (Friedman 2005: 459). Rose further notes that while companies are becoming increasingly specialized to meet market demands, this specialized knowledge will only address parts of any meaningful business or social challenge, which means that innovation comes from putting specialties together in new and different combinations (Friedman 2005: 457).

Johansson (2004: 2) argues that companies need to step into the intersection of fields, disciplines, and cultures to combine existing concepts into extraordinary new ideas, which implies that we need to harness the knowledge and intelligence of people who are not "officially" on the team, who are not "supposed" to have an opinion, and who are not "familiar with" the specifics of the particular project. To us, this seems like an excellent pool of resources for innovation, if we can utilize it at a low overhead. 
At Stanford University's “d.school," this integration of perspectives is visible in their ambition to create "T-shaped" people, who "maintain the depth and focus of a single discipline while adding a 'crossbar' of design thinking that drives the integration of multiple perspectives into solving real problems" (Winograd 2008). The vertical part of the $\mathrm{T}$ represents depth in a particular discipline and the horizontal part of the T represents a broader "empathy" when it comes to respecting, valuing, and embracing a diverse set of disciplines and perspectives. We believe that Engineering 2.0 is largely about providing lightweight technologies that facilitate the "empathic discovery" of knowledge in a wide variety of knowledge sources spread across the many boundaries of the VE.

\subsubsection{From Teams to Crowds}

On the web, how many people that link to a particular page is an indicator of how "good," "interesting" or "useful" that page is, but many corporate intranets do not allow their knowledge workers to create such links between the material they produce. Since a VE is a highly distributed work environment, there is a problem of achieving critical mass in knowledge creation, sharing, and discovery. While the number of knowledge workers in the enterprise might be very high, "knowing who knows" is more difficult than before due to the fragmentation and distribution of knowledge across the enterprise. As noted before intersectional innovation means that the notion of "what a team is" has to be reconsidered.

Engineering 2.0 implies that the innovation ecosystem of a VE includes "open and amorphous networks of peers" (Tapscott and Williams 2006: 257), where the people who contribute with knowledge might not be a part of the team or even the organization, and where community-developed answers and ideas play a major part. If we consider the characteristics of functional product development in VEs, we can actually see that some of the challenges of that context, i.e., related to diversity and distribution of knowledge workers, are turned into significant opportunities. To tap into the wisdom of crowds, you should keep social ties loose, keep yourself exposed to as many diverse sources as possible, and participate in groups that range across hierarchies (Surowiecki 2004). Engineering 2.0 technologies offer the potential to leverage on "spontaneous and decentralized forms of mass collaboration" (Tapscott and Williams 2006) in a self-organized way.

Flipping the "knowing who knows" concept upside-down, it is also very important, from a user perspective, to "know who should know." Very often, knowledge is generated in several parts of the organization, without being properly captured, stored, or shared. This often happens because people cannot recognize the value of this knowledge to others, and are not aware of which people in the organization that can be potentially interested in it. Knowing who "should know," is a crucial topic related to knowledge generation and exchange in a cross-company environment. The loose connection between the partners and the absence of personal networking is one of the main reasons that the generated knowledge may not be fully utilized in the design process. 
An interesting example of how knowledge may be distributed across the enterprise and how serendipitous knowledge discovery plays a crucial role in the actual product development process has been proposed by one of our informants working in the development of manufacturing tools. Companies in the metal cutting industry are trying to reinforce their business by providing customers not only with tools and inserts, but also with the knowledge they need to use these tools in the most efficient way.

[I]f you lower the purchase price of the tools by 30 percent, the customer will save 1 percent of the cost of the component. If he buys a better tool and increases tool life by 50 percent, he lowers the cost of the component by 1 percent. But if instead he buys a better performing tool and speeds up by increasing cutting data then he can reduce the cost of the component by 15 percent. (Abberley 2005)

Such applications have the aim to add value to the customer production process by providing examples of how to properly run a machining operation in the specific customer contest. Sometimes, however, customers may discover applications that are even more efficient than the ones suggested by the manufacturer.

One of the application engineers we have interviewed told us the story about a customer who has tried to adapt a turbine blade machining application to his lowpower machine. The customer finally got significant improvements by radically modifying the machining settings in terms of tools, feed, and speed. After a while, a technician visiting the customer shop floor had the occasion to see the new application and to make a movie, which was then stored in a local database. After several months, a spontaneous and informal meeting held at the margins of a training session activity gave the technician the chance to talk to one of the persons responsible for application development and show him what he had found during his visit. The movie had been further analyzed by the application development engineers and stored with other relevant material in the common application database. This example underlines, on one side, the importance of serendipitous knowledge discovery, while on the other side it shows how crucial it may be to know who should know, in order to exploit knowledge assets at the earliest possible time.

From the metal cutting industry, we found two other examples of user-generated solutions that might more easily be put to common good through the deployment of lightweight technologies. A is an experienced product-development engineer working on insert design. He told us that, in order to rank and sort out good or bad knowledge elements, he usually renames the files contained in the common project database. After accessing a document, he typically put $(+)$ in front of the file name if the content is particularly interesting for the project purpose, $(=)$ if the description may be useful during the development of the new tool, or (-) if the file does not provide any crucial knowledge to fulfill the project goals.

$\mathrm{B}$ is a newcomer at the application development department. B has been assigned to a project that focuses on the possibility to reduce residual surface stress after turning. He started to look for people in the company who could support him with a particular X-ray analysis. Since B was new to the company, his first thought was to ask more experienced people, trying to access their network of expertise, but the effort was unsuccessful. Then he tried to make a keyword search in the corporate 
online contacts book. Although the contact book contained detailed people profiles, the search was not successful either, for two main reasons. First, it was not possible to retrieve information meaningful enough regarding people competences and past experiences. Second, it was difficult to find relevant people through the keyword search, since they were tagged in many different ways (using röntgen instead of roentgen, or $x$-ray, $x$-rays, radiation, radiography, etc.). In the end, B kept in touch with one of the colleagues in his former company, an expert in X-ray equipment. This colleague could refer B to other colleagues that have previously worked with the company, and these people were finally able to give $\mathrm{B}$ the contact information he was looking for.

\subsection{Conclusions}

A crucial point we would like to make here is that we believe that engineering, in the context described in this paper, is moving back and forth between "problem solving" and "prediction." When developing "functions" that are to be included in total life-cycle commitments, engineers are working with a multitude of actors across the value chain. They need to, collaboratively, figure out how to approach ill-defined problems, and in cases where it is just not possible to reach an agreeable solution, or even shared understanding about what the problem is, they need to make well-founded predictions about what a solution might look like in the future. In our opinion, "heavy-weight" PDM or PLM systems undeniably play a strong role in virtual enterprise collaboration, but we believe that their strengths in data and information management need to be complemented by more lightweight knowledge-sharing systems that are better equipped to enable an open, bottom-up, collective sense-making approach to knowledge sharing, rather than the somewhat controlled, top-down, management approach to knowledge sharing that is common in current industry practice. Both approaches are needed, but we should be clear that we also should expect highly different results from the two. One of the major problems when it comes to knowledge sharing in the VE is the absence of "shared assumptions" - about how we do our jobs; who does them; how coordination is done, etc. - and a major benefit of lightweight technologies is that they allow such shared assumptions to develop through folksonomies and other decentralized, bottom-up approaches. Further, if we pay closer attention to what documents, data, photos, and stories really mean to people, as opposed to what corporate taxonomies and databases they should be put into, what management thinks is most important at any given time, or what the company's product portfolio has looked like in the past - then we can start exploring the true potential of mass collaboration and peer production in a VE context.

We would like to conclude that the notion of Engineering 2.0 is something different from "traditional" engineering and product development. The organization is different, the team composition is different, the objectives are different, and the responsibilities are different. In our opinion, the technologies most suitable for effective knowledge sharing will be different, too. 


\section{References}

Abberley (2005).The 15 billion dollar question! American Machinist. September 11 http://www.americanmachinist.com/StateOfManufacturing/ArticleDraw.aspx?HBC=StateOfManufacturing\&N $\mathrm{IL}=$ False $\&$ CID $=11583 \&$ OASKEY $=$ Issue.

Ackerman, M.; Pipek, V.; Wulf, V. Editors (2003). Sharing Expertise, Beyond Knowledge Management. Massachusetts Institute of Technology. USA.

Bains, T.S., Lightfoot, H.W., Williams, G. and Greenough, R. (2007). State-of-the-art in lean design engineering; a literature review on white collar lean. Int. Journal of Mechanical Engineering, Vol.221-Part B. 1543-1552.

Boart, P. (2005). Life Cycle Simulation Support for Functional Products. Licentiate Thesis. Luleå University of Technology. ISSN 1402-1757, ISRN LTU-LIC--05/20.

Brandenburger, A.M. and Nalebuff, B.J. (1997). Co-Opetition: A Revolution Mindset That Combines Competition and Cooperation: The Game Theory Strategy That's Changing the Game of Business. New York: Doubleday/Currency.

Byrne, J. (1993). The Virtual Corporation. Business Week. Feb 8. pp 98-104.

Chen, D. and Daclin, N. (2006). Framework for enterprise interoperability. Proceedings of the International Workshop on Enterprise Integration, Interoperability and Networking EI2N'2006, Bordeaux, France.

Chen, D. and Doumeingts, G. (2004). European Initiatives to develop interoperability of enterprise applications - basic concepts, framework and roadmap. Journal of Annual reviews in Control, Vol. 27(2). 151-160.

Friedman, T. (2005). The World is Flat: A Brief History of the Twenty-First Century. Farrar, Straus and Giroux, New York.

Golder S.A. and Huberman, B.A. (2005) The Structure of Collaborative Tagging Systems. Technical Report, Information Dynamics Lab, HP Labs.

Granovetter, M. (1973). The Strength of Weak Ties. American Journal of Sociology, Vol. 78. No. 6. 1360-1380.

Grudin, J. (2006). Enterprise knowledge management and emerging technologies'. HICSS '06: Proceedings of the 39th Annual Hawaii International Conference on System Sciences, Washington, DC, USA. 57-71.

Johansson, F. (2004). The Medici Effect: Breakthrough Insights at the Intersection of Ideas, Concepts, and Cultures. Boston: Harvard Business School Press.

Kim, S-H., Cohen, M.A., Netessine, S. (2007). Performance Contracting in After-Sales Service Supply Chains. Management Science. Vol. 53. No. 12. 1843-1858.

Larsson, A. (2005). Engineering Know-Who: Why Social Connectedness Matters to Global Design Teams. Doctoral Thesis. Luleå University of Technology, ISSN 1402-1544, ISRN LTU-DT--05/19.

Marchionini, G. (2006). Exploratory Search: From Finding to Understanding. Communications of the ACM, Vol. 49. No. 4. 41-46.

Mayfield, R. (2007). Talk at PARC Forum. In the "Going Beyond 2.0" Speaker Series, http:// www.parc.com/events/forum/, November 15.

McAfee, A. (2006). Enterprise 2.0: The Dawn of Emergent Collaboration. MIT Sloan Management Review, Vol. 47. No. 3. 21-28

McAfee, A. (2007). How to Hit the Enterprise 2.0 Bullseye. Blog Post, http://blog.hbs.edu/faculty/ macafee/, November 3.

McAfee, A. (2008). Talk at PARC Forum. In the "Going Beyond 2.0" Speaker Series, http://www. parc.com/events/forum/, February 21.

Mello, S. (2002). Customer-centric product definition: the key to great product development. AMACOM, USA.

O'Reilly, T. (2005). What is web 2.0: Design Patterns and Business Models for the next Generation of Software. Social Science Research Network Working Paper Series. 
Surowiecki, J. (2004). The Wisdom of Crowds: Why the Many Are Smarter Than the Few and How Collective Wisdom Shapes Business, Economies, Societies and Nations. Doubleday, New York.

Tang, J., Drews, C., Smith, M., Wu, F., Sue, A. and Lau. T. (2007). Exploring Patterns of Social Commonality Among File Directories at Work. Proceedings of CHI'07, San Jose, CA, USA, April 28-May 3.

Tapscott, D., Williams, A.D. (2006). Wikinomics: How Mass Collaboration Changes Everything. Penguin Group, New York.

Tomkins, C. (2001). Interdependencies, trust and information in relationships, alliances and networks. Accounting, Organizations and Society, Vol. 26. 161-191.

Vander Wal, T. (2007). Folksonomy. http://www.vanderwal.net/folksonomy.html

von Hippel, E. (1986). Lead Users: An Important Source of Novel Product Concepts. Management Science. Vol. 32. No. 7. 791-805.

Winograd, T. (2008). Design Education for Business and Engineering Management Students: A New Approach. Interactions. January/February. 